\title{
Serum markers for asymptomatic atherosclerosis in Egyptian psoriatic patients: study controlled by Doppler estimation of carotid intima-media thickness
}

\author{
Hanan Hassan Sabry' \\ Jehan Hassan Sabry ${ }^{2}$ \\ Aliaa El Husseiny Daifalla' \\ Essam Mohamed Akl' \\ Ahmed Mohamed Hamed' \\ Ahmed Abd Allah Torky ${ }^{3}$ \\ 'Department of Dermatology, \\ Venereology and Andrology, Faculty \\ of Medicine, Benha University, Benha, \\ Egypt; ${ }^{2}$ Department of Clinical and \\ Chemical Pathology, Faculty of \\ Medicine, Benha University, Benha, \\ Egypt; ${ }^{3}$ Department of Radiology, \\ Faculty of Medicine, Benha University, \\ Benha, Egypt
}

This article was published in the following Dove Press journal: Vascular Health and Risk Management

Background: The aim of the study was to measure serum levels of endocan, myeloperoxidase (MPO), pentraxin 3 (PTX3) and 1,25-dihydroxyvitamin $\mathrm{D} 3\left(1,25(\mathrm{OH})_{2} \mathrm{D}_{3}\right)$ in psoriatic patients and to study their correlations with carotid intima-media thickness (CIMT) in trial to evaluate predictability of these parameters in diagnosing asymptomatic atherosclerosis (AAS).

Patients and methods: Seventy-five psoriasis patients and 75 control subjects underwent complete clinical examination and Doppler estimation of CIMT using thickness of $0.9 \mathrm{~mm}$ as cutoff point for diagnosis of AAS. Blood samples were collected for determination of fasting blood glucose, lipid profile and serum C-reactive protein (CRP), endocan, MPO, PTX3 and $1,25(\mathrm{OH})_{2} \mathrm{D}_{3}$.

Results: Estimated blood low-density lipoprotein cholesterol (LDL-c) and serum CRP, PTX3, MPO and endocan levels were significantly higher, while blood high-density lipoprotein cholesterol (HDL-c) and serum $1,25(\mathrm{OH})_{2} \mathrm{D}_{3}$ levels were significantly lower in patients than in controls. CIMT showed significant positive correlation with disease severity and duration; patients' age; and endocan, MPO, LDL-c, PTX3 and CRP levels, and significant negative correlation with HDL-c and $1,25(\mathrm{OH})_{2} \mathrm{D}_{3}$ levels. Regression analysis defined high serum endocan and MPO, low serum $1,25(\mathrm{OH})_{2} \mathrm{D}_{3}$ and increased disease severity as significant predictors of high CIMT. Conclusion: Elevated serum levels of endocan and MPO and low $1,25(\mathrm{OH})_{2} \mathrm{D}_{3}$ levels may underlie the development of psoriasis-related cardiac manifestations. Elevated serum endocan and low $1,25(\mathrm{OH})_{2} \mathrm{D}_{3}$ levels could be used as early predictors of increased CIMT, which is a pathognomonic feature of AAS.

Keywords: endocan, vitamin D, myeloperoxidase, carotid intima-media thickness

\section{Introduction}

Psoriasis is an autoimmune chronic inflammatory disease of skin and joints with significantly high morbidity. Severe psoriatic patients have increased risk of early atherosclerosis (AS). ${ }^{1}$

Intima-media thickness (IMT) is defined as a double-line, lumen-intima and media-adventitia interface; its pattern is visualized by $2 \mathrm{D}$-Echo on both walls of the common carotid artery in a longitudinal view. The use of carotid ultrasound was recommended for identifying subclinical AS and evaluating the cardiovascular (CV) risk in asymptomatic individuals. Carotid IMT (CIMT) was found to be effective in detecting early non-calcified subclinical AS changes. ${ }^{2}$ The ESH/ESC hypertension guidelines documented that CIMT $>0.9 \mathrm{~mm}$ has been re-confirmed as a marker of AAS. ${ }^{3}$
Hamed

Department of Dermatology,

Venereology and Andrology, Faculty of

Medicine, Benha University, No. 5 El

Kobry Street, Benha 13513, Egypt

Tel +201005239888

Email ahmedhamed06@yahoo.com 
Endocan is a human endothelial cell-specific molecule with a capacity to inhibit leukocytes binding to the vascular endothelium and promote angiogenesis; so, it may be implicated in pathogenesis of various inflammatory diseases. Endocan as a marker of endothelial dysfunction reflecting ongoing vascular inflammation has an important role in pathogenesis of hypertension. ${ }^{4}$

Vitamin D insufficiency is related to vascular smooth muscle cell proliferation, endothelial cell dysfunction as well as vascular and myocardial cell calcification. It is also related to prehypertension, independent of body mass index (BMI), serum cholesterol, CRP and estimated glomerular filtration rate through undefined mechanism; it seems to be involved not only in regulation of the renin-angiotensin-aldosterone system but also in stimulation of systemic and vascular inflammation, increase in insulin resistance and expression of the natriuretic peptide receptor. ${ }^{5}$

Myeloperoxidase (MPO) enzyme is physiologically expressed in circulating neutrophils, monocytes and some tissue macrophages. MPO produces hypo-halogenated acids as hypochlorous acid, which is a key component of the innate immune response with an indispensable role in microbial killing. However, extracellular release of enzymes, acids and oxidizing species produced during the inflammatory process can cause tissue damage, which lead to inflammatory syndromes such as hay fever, AS, rheumatoid arthritis, Parkinson's disease and Alzheimer's disease. ${ }^{6}$

Pentraxin 3 (PTX3) is a protein synthesized by mononuclear macrophages/phagocytes upon exposure to various inflammatory signals. PTX3 is highly expressed in vascular cells and myocardial cells and plays a CV protective effect. PTX3 may represent a new marker in vascular pathology for local vascular inflammation and CV system disorders and correlates with the risk of developing vascular events. ${ }^{7}$

\section{Aim of work}

The aim of the study was to measure serum levels of endocan, MPO, PTX3 and 1,25-dihydroxyvitamin D3 (1,25(OH) $\left.)_{3}\right)$ in patients with psoriasis and study their correlations with CIMT in trial to evaluate the predictability of these parameters in diagnosing asymptomatic atherosclerosis (AAS).

\section{Patients and methods}

The current study was conducted at Dermatology, Radiology and Clinical Pathology Departments of Benha University Hospital from January 2016 to March 2017. The study was approved by the Local Ethics Committee on Research involving human subjects of Benha Faculty of Medicine, and all enrolled patients signed fully informed consent forms before study attendance.

All psoriasis patients underwent preliminary evaluation for inclusion and exclusion criteria. This study included generalized plaque psoriasis patients with Psoriasis Area and Severity Index (PASI) score $>8$ receiving neither systemic medications for at least 1 month nor topical medications for at least 2 weeks. Exclusion criteria included acute guttate or drug-induced psoriasis; obesity; evident hypertension; severe renal, hepatic and cardiac diseases; other chronic inflammatory diseases and cancer. Patients maintained on supplementary vitamin D therapy, anti-inflammatory drugs, or immuno-promoting drugs were also excluded.

The study included 75 age- and sex-matched normal volunteers serving as the control group selected from those attending hospital blood bank for blood donation after passing the preliminary investigations for blood donation and fulfilling the current study inclusion and exclusion criteria.

All patients and controls were subjected to thorough medical history and clinical examination, searching for clinical manifestations suggestive of systemic diseases, paying special attention to blood pressure measurement and BMI calculation (BMI of $25.0-29.9 \mathrm{~kg} / \mathrm{m}^{2}=$ overweight; and BMI $\geq 30.0 \mathrm{~kg} / \mathrm{m}^{2}=$ obese). Disease-related data including duration of disease, history of systemic therapy, stability and severity of the disease were determined. Severity of psoriasis was assessed using PASI score, which was used to express psoriasis severity, induration, erythema and scaling on body surfaces of each patient, with PASI score $<7,7-12$ and $>12$ indicating mild, moderate and severe disease. ${ }^{8}$

\section{Measurement of carotid intima-media thickness}

The carotid arteries were scanned in transverse sections starting from the origins of the common carotid arteries passing carotid sinuses, internal carotid arteries and external carotid arteries, and then examined for carotid lesions in longitudinal sections at different angles. ${ }^{9}$ Ultrasound imaging was performed by a B-mode ultrasonography (Toshiba Xario 200) using a linear probe (PLT-704 SBT) with a center frequency of $7.5 \mathrm{MHz}$.

\section{Blood sampling}

Overnight fasting venous blood sample $(10 \mathrm{~mL})$ were withdrawn from each patient and control; blood was left to clot and centrifuged for 10 minutes at $3000 \mathrm{rpm}$. Then, serum was separated and kept at $-20^{\circ} \mathrm{C}$ till assayed. 


\section{Laboratory investigations}

1. Fasting blood glucose (FBG), serum total cholesterol (TC), triglycerides ( $\mathrm{Tg}$ ) and high-density lipoprotein cholesterol (HDL-c) levels were determined using BS300 system auto-analyzer applying enzymatic colorimetric methods. Low-density lipoprotein cholesterol (LDL-c) value was calculated according to Friedwald's equation: LDL-c $=\mathrm{TC}-(\mathrm{HDL}-\mathrm{c}+[\mathrm{Tg} / 5]) \cdot{ }^{10}$

2. Serum C-reactive protein (CRP) was estimated using CRP-latex, a rapid slide agglutination procedure.

3. ELISA techniques were chosen for determination of serum biomarkers: Boster Endocan (ECSM1) human ELISA kit (Boster Biological Technology, Pleasanton, CA, USA) for endocan, ${ }^{11}$ Cayman Myeloperoxidase (human) ELISA kit (Cayman Chemical Co., Ann Arbor, MI, USA) for MPO, ${ }^{12} \mathrm{Abcam}$ Pentraxin 3 Human ELISA Kit (Abcam Co., Cambridge, UK) for PTX $3^{13}$ and 1,25 dihydroxyvitamin D ELISA Kit (SunRed Biotechnology, Shanghai, People' Republic of China) for vitamin D. ${ }^{14}$

\section{Statistical analysis}

Obtained data were presented as mean $\pm \mathrm{SD}$, ranges, numbers and ratios. Results were analyzed using one-way ANOVA with post hoc Tukey's HSD test and chi-squared test $\left(\chi^{2}\right.$ test). Possible relationships were investigated using Pearson linear regression analysis. Regression analysis (stepwise method) was used for stratification of studied parameters as significant predictors for the target disease. Statistical analysis was conducted using SPSS (Version 15, 2006) for Windows statistical package. $p$-value $<0.05$ was considered statistically significant.

\section{Results}

The study included 75 psoriasis patients who fulfilled the inclusion criteria and 75 control subjects. Age, sex, BMI and smoking status showed non-significant $(p>0.05)$ difference between patients and controls. According to PASI scoring, 28 patients had severe psoriasis and 42 patients had moderate psoriasis with a mean PASI score of $12.3 \pm 4.6$ (range: 8-31). Six patients had positive family history for autoimmune diseases and 10 patients had history of systemic therapy (Table 1).

Using thickness of $0.9 \mathrm{~mm}$ as cutoff point for diagnosis of AAS, Doppler estimation of CIMT defined 18 patients with bilateral CIMT of $<0.9 \mathrm{~mm}$ and 17 patients with CIMT of $0.9 \mathrm{~mm}$ ( $10 \mathrm{on}$ left, 6 on right and one bilateral). On the other side, 25 patients had bilateral CIMT of $>0.9 \mathrm{~mm}$ (Figure 1), 12 patients had CIMT of $>0.9 \mathrm{~mm}$ on right and 3 patients on left carotid (Figure 2). Mean CIMT of the right carotid was $0.955 \pm 0.25$ (range: $0.47-1.6 \mathrm{~mm}$ ), and mean CIMT of the left carotid was $0.858 \pm 0.199$ (range: $0.5-1.3 \mathrm{~mm}$ ).

Levels of FBG, TC and Tg were non-significantly $(p>0.05)$ higher in patients than in controls. On contrary, serum levels of HDL were significantly $(p=0.035)$ lower

Table I Demographics and clinical characteristics of patients and controls

\begin{tabular}{|c|c|c|c|}
\hline \multicolumn{2}{|l|}{ Data } & \multirow{2}{*}{$\begin{array}{l}\text { Controls } \\
44.5 \pm 11.4(29-64)\end{array}$} & \multirow{2}{*}{$\begin{array}{l}\text { Patients } \\
45.2 \pm 8.4(22-59)\end{array}$} \\
\hline Age (years) & & & \\
\hline Sex; M:F & & $11: 9$ & $38: 37$ \\
\hline \multirow[t]{3}{*}{ Body mass index data } & Weight (kg) & $80.4 \pm 10.1$ & $85.1 \pm 8.4$ \\
\hline & Height $(m)$ & $169.9 \pm 3.5$ & $169.5 \pm 2.9$ \\
\hline & Body mass index $\left(\mathrm{kg} / \mathrm{m}^{2}\right)$ & $27.9 \pm 3.5$ & $29.6 \pm 4.2$ \\
\hline \multirow[t]{3}{*}{ Smoking } & Never & $13(65 \%)$ & $36(48 \%)$ \\
\hline & Ex-smoker & $3(15 \%)$ & $23(30.7 \%)$ \\
\hline & Current smoker & $4(20 \%)$ & $16(21.3 \%)$ \\
\hline \multirow[t]{5}{*}{ Duration of psoriasis (years) } & $\leq 5$ & & $40(53.3 \%)$ \\
\hline & $6-10$ & & $17(22.7 \%)$ \\
\hline & $\geq 10-15$ & & $5(6.7 \%)$ \\
\hline & $>15$ & & $13(17.3 \%)$ \\
\hline & Mean & & $7.9 \pm 7.2(I-25)$ \\
\hline \multirow[t]{3}{*}{ PASI } & Moderate & & $42(60 \%)$ \\
\hline & Severe & & $28(40 \%)$ \\
\hline & Mean & & $12.3 \pm 4.6(8-3 \mid)$ \\
\hline \multicolumn{2}{|c|}{ Past history of systemic therapy } & & $10(13.3 \%)$ \\
\hline \multicolumn{2}{|c|}{ Positive family history for autoimmune diseases } & & $6(8 \%)$ \\
\hline
\end{tabular}

Note: Data are presented as mean \pm SD and numbers; ranges and percentages are in parenthesis.

Abbreviations: PASI, Psoriasis Area Severity Index; M:F, male:female. 


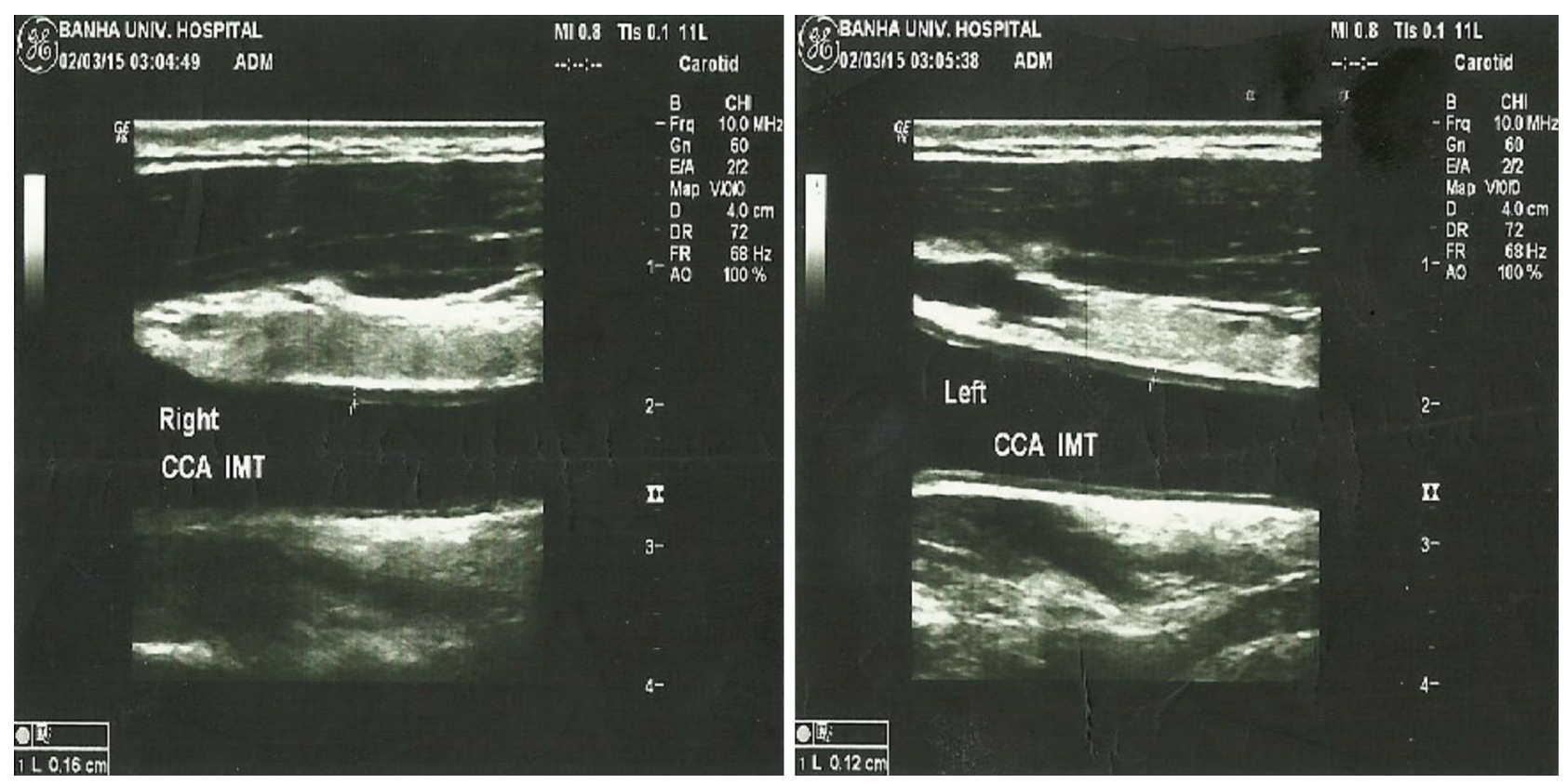

Figure I Color Doppler estimation of CIMT in a psoriatic patient ( $1.2 \mathrm{~mm}$ on left side and $1.6 \mathrm{~mm}$ on the right side).

Abbreviation: CIMT, carotid intima-media thickness.

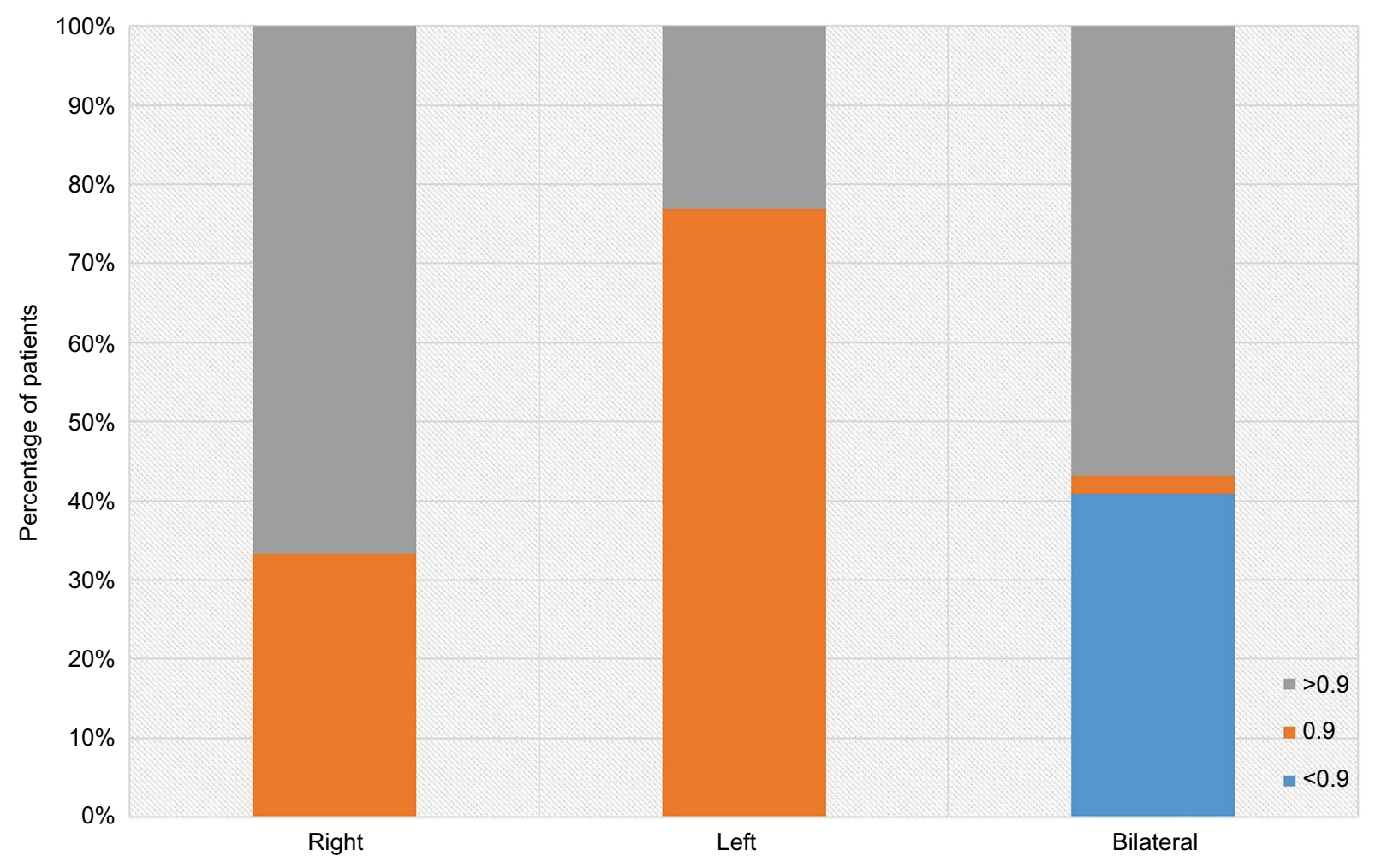

Figure 2 Patients distribution according to grades of CIMT thickness and its laterality. Abbreviation: CIMT, carotid intima-media thickness.

and LDL levels were significantly $(p=0.001)$ higher in than in controls, while serum $1,25(\mathrm{OH})_{2} \mathrm{D}_{3}$ levels were patients compared to controls. Serum CRP, PTX3, MPO significantly lower in patients than in controls (Table 2, and endocan levels were significantly higher in patients Figures 3 and 4). 
Table 2 Laboratory parameters estimated in patients compared to controls

\begin{tabular}{|c|c|c|c|c|}
\hline Parameter & & Controls & Patients & $p$-value \\
\hline FBS (mg/dL) & & $110.2 \pm 7$ & $114 \pm 47$ & 0.731 \\
\hline \multirow[t]{4}{*}{ Lipid profile } & Cholesterol (mg/dL) & $183.1 \pm 23.7$ & $191.8 \pm 36.5$ & 0.312 \\
\hline & Triglycerides $(\mathrm{mg} / \mathrm{dL})$ & $134.1 \pm 44.2$ & $|4| .3 \pm 49.1$ & 0.556 \\
\hline & $\mathrm{HDL}(\mathrm{mg} / \mathrm{dL})$ & $38.6 \pm 2.7$ & $36.4 \pm 4.3$ & $0.035^{*}$ \\
\hline & $\mathrm{LDL}(\mathrm{mg} / \mathrm{dL})$ & $117.6 \pm 26.4$ & $127.1 \pm 34.1$ & $0.001 *$ \\
\hline CRP (mg/L) & & $6.05 \pm 0.8$ & $25.3 \pm 31.6$ & $0.0077^{*}$ \\
\hline Pentraxin $3(\mathrm{ng} / \mathrm{mL})$ & & $1.37 \pm 0.45$ & $2.5 I \pm 0.75$ & $0.001 *$ \\
\hline MPO (ng/mL) & & $2.76 \pm 0.62$ & $4.57 \pm 2.17$ & $0.001 *$ \\
\hline Endocan (ng/L) & & II $5.65 \pm 44.5$ & $|49.1| \pm 2|.23|$ & $0.0039 *$ \\
\hline $\mathrm{I}, 25(\mathrm{OH})_{2} \mathrm{D}_{3}(\mathrm{pmol} / \mathrm{L})$ & & $246.5 \pm 44.5$ & $107.93 \pm 12.33$ & $0.001 *$ \\
\hline
\end{tabular}

Notes: * $p$-value $\leq 0.05$ indicates significant difference; $p$-value $>0.05$ indicates non-significant difference. Data are presented as mean $\pm S D$.

Abbreviations: I,25(OH) ${ }_{2} \mathrm{D}_{3}$, I,25-dihydroxyvitamin D3; CRP, C-reactive protein; FBS, fasting blood sugar; HDL, high-density lipoprotein; LDL, low-density lipoprotein; MPO, myeloperoxidase.

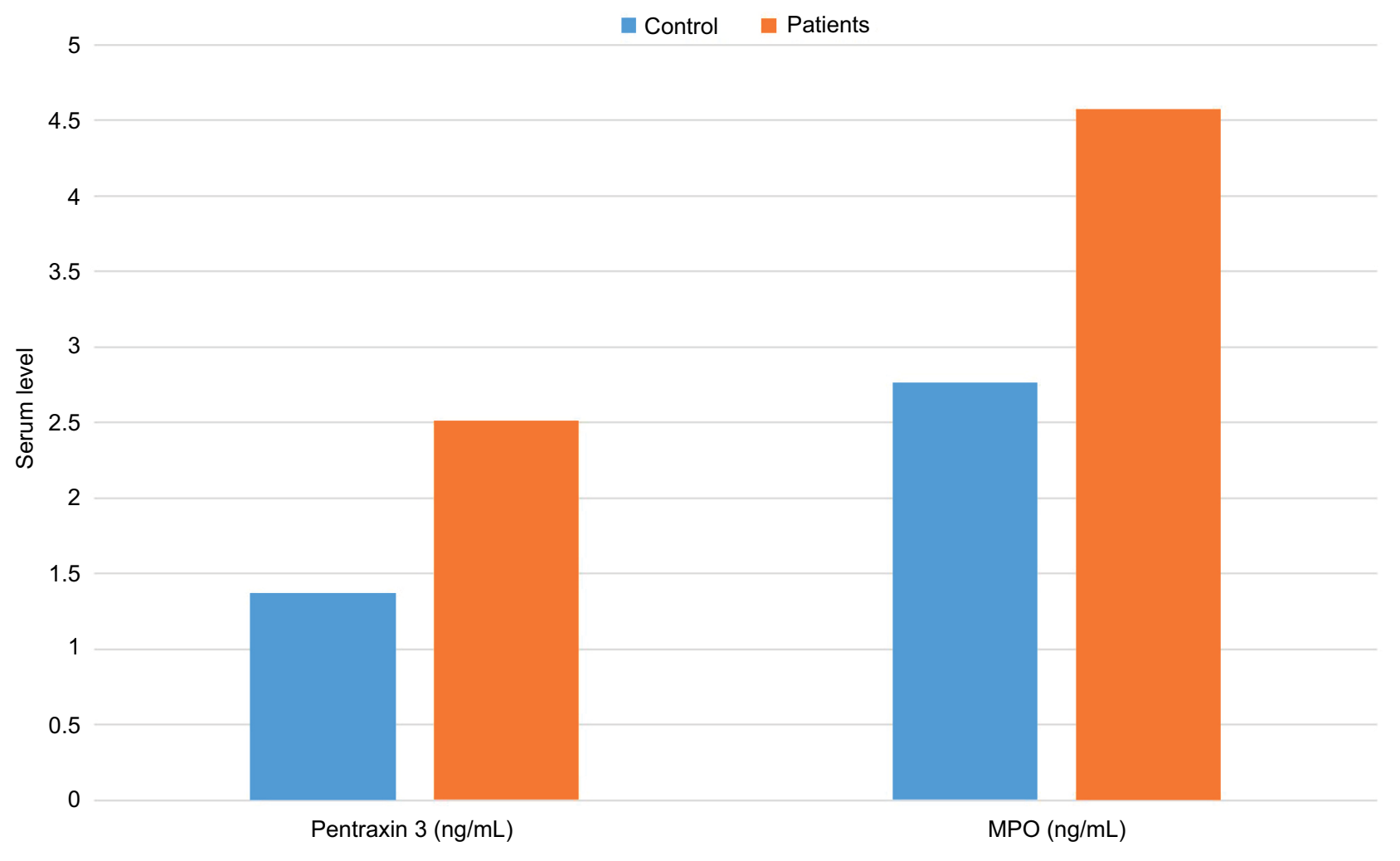

Figure 3 Mean serum pentraxin 3 and MPO levels estimated in patients and controls. Abbreviation: MPO, myeloperoxidase.

CIMT showed positive significant correlation with disease severity, calculated PASI, disease duration and patients' age in decreasing order of significance. Moreover, determined CIMT showed significant positive correlation with serum levels of endocan, MPO, LDL-c, PTX3 and CRP in decreasing order of significance, while showed significant negative correlation with serum $1,25(\mathrm{OH})_{2} \mathrm{D}_{3}$ levels (Table 3). Regression analysis defined high serum endocan and MPO levels, low serum $1,25(\mathrm{OH})_{2} \mathrm{D}_{3}$, levels and increased disease severity as significant predictors of high CIMT (Table 4).

\section{Discussion}

Doppler examination of both common carotid arteries defined 40 psoriatic patients with CIMT of $>0.9 \mathrm{~mm}$, which is a cutoff point for diagnosis of AAS. ${ }^{3}$ In line with these findings, Bańska-Kisiel et al ${ }^{1}$ reported a high prevalence of early AS in 
- Control $\square$ Patients

250

200

$\frac{\bar{\Phi}}{\frac{\Phi}{2}} 150$

100

50

0
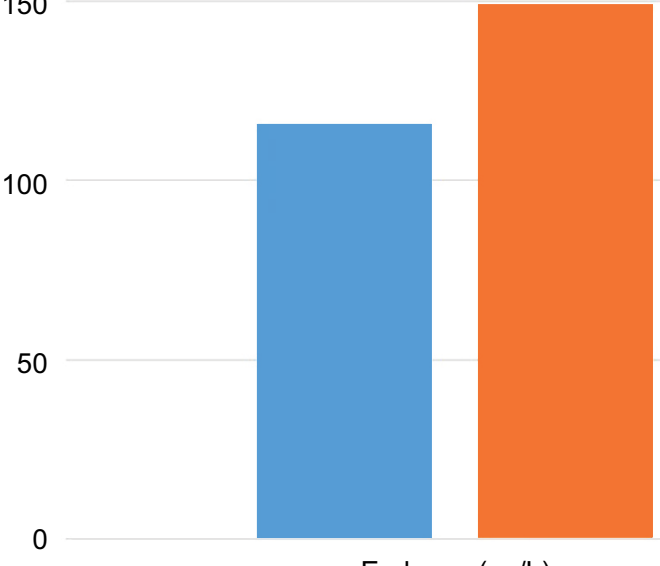

Endocan (ng/L)

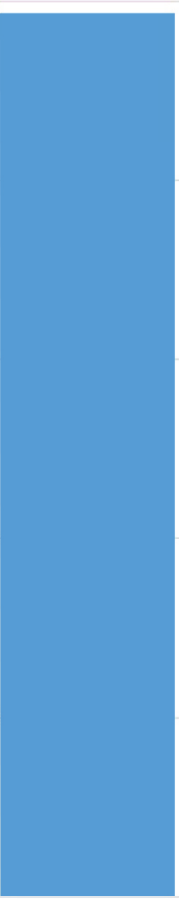

$1,25(\mathrm{OH})_{2} \mathrm{D}_{3}(\mathrm{pmol} / \mathrm{L})$

Figure 4 Mean serum endocan and $\mathrm{I}, 25(\mathrm{OH})_{2} \mathrm{D}_{3}$ levels estimated in patients and controls.

Abbreviation: $1,25(\mathrm{OH})_{2} \mathrm{D}_{3}, \mathrm{l}, 25$-dihydroxyvitamin $\mathrm{D} 3$.

Table 3 Correlation between determined CIMT and clinical and laboratory findings

\begin{tabular}{lll}
\hline \multicolumn{2}{l}{ Pearson's correlation analysis of CIMT } \\
\hline Variable & $\boldsymbol{r}$ & P-value \\
\hline Age & 0.274 & 0.017 \\
BMI & 0.064 & 0.583 \\
Duration of disease & 0.344 & $0.003^{*}$ \\
PASI & 0.345 & $0.002^{*}$ \\
Pentraxin 3 & 0.302 & $0.007^{*}$ \\
Endocan & 0.404 & $0.0002^{*}$ \\
MPO & 0.397 & $0.0004^{*}$ \\
I,25(OH) ${ }_{2} \mathrm{D}_{3}$ & -0.370 & 0.00 I $^{*}$ \\
CRP & 0.256 & $0.026^{*}$ \\
FBS & 0.046 & 0.692 \\
Total cholesterol & 0.195 & 0.094 \\
Triglyceride & 0.073 & 0.536 \\
HDL & 0.090 & 0.440 \\
LDL & 0.324 & $0.005^{*}$ \\
\hline Notes
\end{tabular}

Notes: $r$, Pearson correlation coefficient; ${ }^{*} p$-value $\leq 0.05$ indicates significant correlation; $p$-value $>0.05$ indicates non-significant correlation.

Abbreviations: $1,25(\mathrm{OH})_{2} \mathrm{D}_{3}, \mathrm{I}, 25$-dihydroxyvitamin $\mathrm{D} 3$; BMl, body mass index; CIMT, carotid intima-media thickness; CRP, C-reactive protein; FBS, fasting blood sugar; HDL, high-density lipoprotein; LDL, low-density lipoprotein; MPO, myeloperoxidase; LDL, low-density lipoprotein; PASI, Psoriasis Area Severity Index.

psoriatic patients and concluded that psoriasis may contribute to an accelerated systemic inflammatory cascade resulting in increased risk of $\mathrm{CV}$ events. Fang et $\mathrm{a}^{15}$ suggested that
Table 4 Regression analysis to predict for high CIMT as a measure for atherosclerosis

\begin{tabular}{lllll}
\hline \multicolumn{2}{l}{ Regression analysis } \\
\hline Model & & $\boldsymbol{\beta}$ & $\boldsymbol{t}$ & $\boldsymbol{p}$-value \\
\hline $\mathrm{I}$ & Endocan & 0.377 & 4.196 & $0.000 \mathrm{I}^{*}$ \\
& $\mathrm{I}, 25(\mathrm{OH})_{2} \mathrm{D}_{3}$ & -0.289 & 3.133 & $0.003^{*}$ \\
& $\mathrm{PASI}$ & 0.264 & 2.879 & $0.005^{*}$ \\
& $\mathrm{MPO}$ & 0.242 & 2.666 & $0.010^{*}$ \\
& Endocan & 0.370 & 3.949 & $0.0005^{*}$ \\
& $\mathrm{I}, 25(\mathrm{OH})_{2} \mathrm{D}_{3}$ & -0.322 & $3.37 \mathrm{I}$ & $0.003^{*}$ \\
& $\mathrm{PASI}$ & $0.28 \mathrm{I}$ & 2.947 & $0.008^{*}$ \\
3 & Endocan & 0.385 & 3.917 & $0.0007^{*}$ \\
& $\mathrm{I}, 25(\mathrm{OH})_{2} \mathrm{D}_{3}$ & -0.377 & 3.835 & $0.0008^{*}$ \\
4 & Endocan & 0.404 & 3.774 & $0.0008^{*}$ \\
\hline
\end{tabular}

Notes: $\beta$, standardized beta; $t$-test statistic. ${ }^{*} p$-value $\leq 0.05$ indicates significant predictor, $p$-value $>0.05$ indicates non-significant predictor.

Abbreviations: I,25(OH) $)_{2}$, I,25-dihydroxyvitamin D3; CIMT, carotid intimamedia thickness; MPO, myeloperoxidase; PASI, Psoriasis Area Severity Index.

patients with psoriasis are associated with excessive risk of AAS and monitoring of CIMT may be recommended to identify psoriatic patients at a higher risk for $\mathrm{CV}$ events.

Serum endocan levels were significantly higher in psoriatic patients than in controls with positive significant correlation with both PASI score and estimated CIMT. Regression analysis defined high serum endocan as a positive significant 
predictor for presence of AAS with CIMT of $\geq 0.9 \mathrm{~mm}$, and so high serum endocan levels could be considered as early predictor for asymptomatic cardiac diseases. In line with these data; Balta et $\mathrm{al}^{4}$ found serum endocan levels to be correlated with CIMT and concluded that circulating endocan correlates with CV risk in hypertensive patients. Recently, Kundi et $\mathrm{al}^{16}$ and Efe et $\mathrm{al}^{17}$ found that high endocan levels were significantly and independently associated with the presence of slow coronary flow rates ${ }^{16}$ and cardiac syndrome $\mathrm{X},{ }^{17}$ and can accurately predict both diagnoses with high sensitivity and specificity rates. Moreover, Lv et al ${ }^{18}$ concluded that serum endocan levels may be a useful biomarker for the early diagnosis of AAS.

The present study revealed that serum $1,25(\mathrm{OH})_{2} \mathrm{D}_{3}$ levels were significantly lower in patients than in controls with negative significant correlation with CIMT, and regression analysis defined low serum $1,25(\mathrm{OH})_{2} \mathrm{D}_{3}$ levels as a significant predictor of high CIMT. Similarly, Al-Mutairi et al $^{19}$ detected low serum vitamin $\mathrm{D}$ and higher blood cathelicidin levels in psoriatic patients than in controls and suggested that these disturbed levels could form a clue in psoriasis pathogenesis, especially in patients who are more likely to develop comorbidities. Gracia et $\mathrm{al}^{20}$ reported that low vitamin D levels were positively associated with atheromatosis progression in patients with chronic kidney disease. Recently, in a study by Choi et al, ${ }^{21}$ serum vitamin D level was negatively associated with carotid AS and increasing serum vitamin D levels decreased the presence of high-risk carotid plaque.

Results of the current study showed significantly higher serum MPO levels in psoriatic patients than in controls with a significant positive correlation with CIMT. High MPO levels were defined as a significant predictor of high CIMT. In agreement with these findings, Cao et $\mathrm{al}^{22}$ detected 2.5fold elevation in serum MPO level in psoriasis patients that correlated with coronary artery calcification, carotid plaque, CIMT and flow mediated dilation. They tried to explain those correlations by lesional skin $\mathrm{CD} 11 \mathrm{~b}^{(+)}$leukocyte activation to generate MPO, which may contribute to elevated serum levels of MPO and concluded that its activity may be an alternative measure of disease burden that underlies the systemic inflammation related to $\mathrm{CV}$ disease. Karbach et $\mathrm{al}^{23}$ using psoriasis animal model detected that dermal overexpression of IL-17A induces systemic endothelial dysfunction, vascular oxidative stress and arterial hypertension, and increases mortality driven mainly by MPO-positive inflammatory cells.

In our study, serum PTX3 levels were significantly higher in patients compared to controls with significant positive correlation with serum CRP and estimated CIMT. Recently, Okan et $\mathrm{al}^{24}$ reported higher serum levels of PTX3 in psoriatic patients compared with controls; PTX3 levels were correlated positively with triglyceride, and very low density lipoprotein cholesterol. Similarly, Uysal et $\mathrm{al}^{25}$ detected elevated serum values for CRP and PTX3 in psoriatic patients and suggested that PTX3 might play a role in pathogenesis of psoriasis and could be used as a marker of disease activity.

Limitations of the study were as follows: 1) small sample size, 2) the regression model did not take into account the predictors of vascular aging and 3) serum levels of markers were not measured in different age groups or in different severity groups of psoriasis.

\section{Conclusion}

Elevated serum levels of endocan and MPO and low $1,25(\mathrm{OH})_{2} \mathrm{D}_{3}$ levels may underlie the development of psoriasis-related cardiac manifestations. Elevated serum endocan and low $1,25(\mathrm{OH})_{2} \mathrm{D}_{3}$ levels could be used as early predictors for high CIMT, a pathognomonic feature of AAS.

\section{Disclosure}

The authors report no conflicts of interest in this work.

\section{References}

1. Bańska-Kisiel K, Haberka M, Bergler-Czop B, Brzezińska-Wcisło L, Okopień B, Gąsior Z. Carotid intima-media thickness in patients with mild or moderate psoriasis. Postepy Dermatol Alergol. 2016;33(4): 286-289.

2. Stein JH, Korcarz CE, Hurst RT, et al; American Society of Echocardiography Carotid Intima-Media Thickness Task Force. Use of carotid ultrasound to identify subclinical vascular disease and evaluate cardiovascular disease risk: a consensus statement from the American Society of Echocardiography Carotid Intima-Media Thickness Task Force. Endorsed by the Society for Vascular Medicine. JAm Soc Echocardiogr. 2008;21(2):93-111.

3. Lorenz MW, von Kegler S, Steinmetz H, Markus HS, Sitzer M. Carotid intima-media thickening indicates a higher vascular risk across a wide age range. prospective data from the Carotid Atherosclerosis Progression Study (CAPS). Stroke. 2006;37(1):87-92.

4. Balta S, Mikhailidis DP, Demirkol S, et al. Endocan--a novel inflammatory indicator in newly diagnosed patients with hypertension: a pilot study. Angiology. 2014;65(9):773-777.

5. Tamez H, Thadhani RI. Vitamin D and hypertension: an update and review. Curr Opin Nephrol Hypertens. 2012;21(5):492-499.

6. Soubhye J, Aldib I, Delporte C, Prévost M, Dufrasne F, Antwerpen PV. Myeloperoxidase as a target for the treatment of inflammatory syndromes: mechanisms and structure activity relationships of inhibitors. Curr Med Chem. 2016;23(35):3975-4008.

7. Garlanda C, Bottazzi B, Moalli F, et al. Pentraxins and atherosclerosis: the role of PTX3. Curr Pharm Des. 2011;17(1):38-46.

8. Schmitt J, Wozel G. The psoriasis area and severity index is the adequate criterion to define severity in chronic plaque-type psoriasis. Dermatology. 2005;210(3):194-199.

9. Yiu KH, Yeung CK, Zhao CT, et al. Prevalence and extent of subclinical atherosclerosis in patients with psoriasis. J Intern Med. 2013;273(3):273-282. 
10. Warnick GR, Knopp RH, Fitzpatrick V, Branson L. Estimating lowdensity lipoprotein cholesterol by the Friedewald equation is adequate for classifying patients on the basis of nationally recommended cutpoints. Clin Chem. 1995;36(1):15-19.

11. Depontieu F, de Freitas Caires N, Gourcerol D, et al. Development of monoclonal antibodies and ELISA specific for the mouse vascular endocan. J Immunol Methods. 2012;378:88-94.

12. Klebanoff SJ. Myeloperoxidase: friend and foe. J Leukoc Biol. 2005;77(5):598-625.

13. Diniz SN, Nomizo R, Cisalpino PS, et al. PTX3 function as an opsonin for the dectin-1-dependent internalization of zymosan by macrophages. J Leukoc Biol. 2004;75 (4):649-656.

14. Wildermutha S, Dittrich K, Schmidt-Gayk H, Zahn I, O’Riordan JL. Scintillation proximity assay for calcitriol in serum without high pressure liquid chromatography. Clin Chim Acta. 1993;220(1):61-70.

15. Fang N, Jiang M, Fan Y. Association between psoriasis and subclinical atherosclerosis: a meta-analysis. Medicine (Baltimore). 2016;95(20):e3576.

16. Kundi H, Gok M, Kiziltunc E, et al. The relationship between serum endocan levels with the presence of slow coronary flow: a cross-sectional study. Clin Appl Thromb Hemost. 2017;23(5):472-477.

17. Efe SC, Demirci K, Ozturk S, et al. Serum endocan levels in patients with cardiac syndrome X. Herz. Epub 2017 Jun 6. doi: 10.1007/ s00059-017-4580-3.

18. Lv Y, Zhang Y, Shi W, et al. The association between endocan levels and subclinical atherosclerosis in patients with type 2 diabetes mellitus. Am J Med Sci. 2017;353(5):433-438.
19. Al-Mutairi N, El Eassa B, Nair V. Measurement of vitamin D and cathelicidin (LL-37) levels in patients of psoriasis with co-morbidities. Indian J Dermatol Venereol Leprol. 2013;79(4):492-496.

20. Gracia M, Betriu À, Martínez-Alonso M, et al; NEFRONA Investigators. Predictors of subclinical atheromatosis progression over 2 years in patients with different stages of CKD. Clin J Am Soc Nephrol. 2016;11(2):287-296.

21. Choi YK, Song SW, Shin BR, Kim JA, Kim HN. Serum vitamin D level is negatively associated with carotid atherosclerosis in Korean adults. Int J Food Sci Nutr. 2017;68(1):90-96.

22. Cao LY, Soler DC, Debanne SM, et al. Psoriasis and cardiovascular risk factors: increased serum myeloperoxidase and corresponding immunocellular overexpression by $\mathrm{Cd} 11 \mathrm{~b}(+) \mathrm{CD} 68(+)$ macrophages in skin lesions. Am J Transl Res. 2013;6(1):16-27.

23. Karbach S, Croxford AL, Oelze M, et al. Interleukin 17 drives vascular inflammation, endothelial dysfunction, and arterial hypertension in psoriasis-like skin disease. Arterioscler Thromb Vasc Biol. 2014;34(12):2658-2668

24. Okan G, Baki AM, Yorulmaz E, Doğru-Abbasoğlu S, Vural P. Serum visfatin, fetuin-A, and pentraxin 3 levels in patients with psoriasis and their relation to disease severity. J Clin Lab Anal. 2016;30(4): 284-289.

25. Uysal S, Yilmaz FM, Karatoprak K, Artüz F, Cumbul NU. The levels of serum pentraxin3, CRP, fetuin-A, and insulin in patients with psoriasis. Eur Rev Med Pharmacol Sci. 2014;18(22):3453-3458.
Vascular Health and Risk Management

\section{Publish your work in this journal}

Vascular Health and Risk Management is an international, peerreviewed journal of therapeutics and risk management, focusing on concise rapid reporting of clinical studies on the processes involved in the maintenance of vascular health; the monitoring, prevention and treatment of vascular disease and its sequelae; and the involvement of

\section{Dovepress}

metabolic disorders, particularly diabetes. This journal is indexed on PubMed Central and MedLine. The manuscript management system is completely online and includes a very quick and fair peer-review system, which is all easy to use. Visit http://www.dovepress.com/ testimonials.php to read real quotes from published authors. 